\title{
Isabel Godoy, activista política perteneciente al pueblo Colla y constituyente electa por medio de los escaños reservados
}

\author{
Claudia Iriarte Rivas (iD \\ Universidad de Chile
}

¿Cuáles piensa usted que son los desafíos de la Convención Constitucional para la resolución del conflicto social e institucional que se presenta actualmente en Chile?

Por cierto, el primer paso es el reconocimiento de la preexistencia y de la plurinacionalidad, que no sea solamente un enunciado, sino que sea, además, reconocida en términos de derechos y garantías. No podemos estar relacionándonos de esta manera, por un lado haciendo un pacto de paz y por otro lado militarizando los territorios que fueron despojados porque Chile se apropió de todo el territorio de los pueblos originarios en el país. El mayor conflicto se acentúa con la resistencia del pueblo nación mapuche.

Nosotros, los pueblos del norte, fuimos casi aniquilados, despojados de nuestros territorios. Fue como cuando llegaba el matón del curso y te quería quitar la silla, no te preguntaba, te la sacaba. Eso mismo nos pasó a nosotros. Se menospreció nuestra cultura, nuestras costumbres, nuestra manera de vivir, nuestra manera de relacionarnos con la naturaleza, y eso es una tremenda violación a los derechos humanos, tanto física como espiritual. A nosotros nos discriminaron, nos violentaron, casi nos exterminaron hasta la lengua, nos impusieron una cultura distinta, hasta un Dios diferente. Nuestra religiosidad nos fue usurpada, ¿y por qué digo usurpada? Porque cuando hacen estas fiestas religiosas, los bailes que hacen son indígenas, fueron tomados de los pueblos originarios y, además, estos fueron obligados a rendir honores a un Dios que no era el propio. Entonces, si hablamos de los derechos humanos de los pueblos indígenas, debemos hablar de que aquí se cometió el genocidio más grande de la historia, mucho más grande de lo que fue el holocausto judío. 
¿Cómo cree usted que debería platearse el sistema de derechos que debe estructurarse en la nueva constitución? ¿Basado en qué principios?

Bueno, nosotros sin tierra y sin agua perdemos nuestra esencia porque nuestra propia existencia emana del agua y de la tierra. Si no se hace un reconocimiento de los territorios y se nos permite a nosotros ser propietarios y decidir cómo vivir, cómo desarrollar nuestra cultura, cómo relacionarnos políticamente, nos están exterminando. Entonces, eso es lo que se espera de esta nueva constitución.

Como dije al comienzo, es un nuevo pacto, un pacto de paz que tiene por primera vez en la historia el Estado de Chile con los pueblos originarios. Nosotros nunca habíamos sido parte de un proceso en el que pudiéramos decir cómo queremos vivir y nunca habíamos tenido la posibilidad real de tener autonomía territorial, porque todos los otros acercamientos que tuvo el Estado de Chile fueron desde la tutelación de derechos y desde la mirada tanto paternalista como proteccionista, que, en el fondo, no era ni tan paternalista ni tan proteccionista, porque lo único que querían era seguir usando nuestros territorios y apropiarse de ellos, mirando nuestros bienes naturales como recursos naturales para la explotación infinita y la realidad es que son bienes finitos.

En ese sentido, ¿diría que más allá del reconocimiento y la plurinacionalidad que usted ha dicho que es fundamental, este reconocimiento abarca todo un nuevo sistema de derechos que significa el conocimiento de los derechos colectivos de los pueblos en la propia constitución?

Exacto. No puede haber un reconocimiento simbólico. Cuando nosotros hablamos de plurinacionalidad estamos hablando de reconocer que no solamente está la nación chilena, sino que existen otras naciones con su propia cultura, su modo de vivir y modo de organización. Nosotros también necesitamos estar incluidos dentro de esa descentralización del poder y ser parte de los poderes del Estado, es decir, que tengamos escaños reservados en todos los estamentos de participación popular, como en el Congreso, en los gobiernos locales y en los gobiernos regionales. Eso es una descentralización de poder y una plurinacionalidad completa porque solamente nos reconocen y dicen: «Chile reconoce la preexistencia de los pueblos originarios», y queda como un bonito título, pero no nos va a servir de nada porque no vamos a ser dueños de nuestro territorio.

Aparte de que sea un Estado plurinacional, nosotros pedimos que sea intercultural, para que no solamente la nación chilena prevalezca como una única cultura, sino que la cultura de las naciones originarias también sea puesta en valor o visibilizada porque, hasta ahora, nuestras costumbres y nuestra cultura han sido visibilizadas desde el folclore y no desde el valor que realmente tiene o la significancia que realmente tiene para los pueblos originarios. 
Dentro de los temas de la estructuración del Estado, ¿qué planteamiento le parece a usted que debería quedar en la constitución en materia de justicia? ¿Han reflexionado, como se establece en derecho comparado, en torno a la idea de dos justicias?

Por supuesto, lo que tenemos más cerca son, por ejemplo, los juicios a los mapuches. Son juzgados desde la mirada colonial, desde la mirada de los tribunales chilenos y no tomando en cuenta su cosmovisión y cultura. Por eso decimos que deben existir tribunales especiales para los pueblos originarios, en los que, al momento de haber un conflicto legal, se tenga en consideración el Convenio 169 de la OIT y sea atendido si el delito está considerado dentro de la cosmovisión pertinente. Por ejemplo, los pueblos originarios vivíamos del guanaco. No estoy diciendo que tengamos que cazar guanacos, porque se encuentra en peligro de extinción, aunque fue la caza del hombre blanco la que los llevó a ese nivel, ya que nuestros ancestros simplemente tomaban lo que necesitaban para vivir, no por deporte, no para venderlos. Es distinto ver a un colla cazando un guanaco para alimentarse que por deporte, porque es parte de nuestra cosmovisión, de nuestras costumbres ancestrales, y para la otra persona no, entonces las personas no pueden ser juzgadas de la misma manera.

Más allá de los desafios para el trabajo que ustedes están enfrentando con respecto a los pueblos indígenas en la Convención Constituyente, ¿ve usted un rol especifico de los escaños reservados en la Convención y en la nueva constitución para enfrentar el conjunto de conflictos sociales no solo relacionados con los pueblos indígenas, sino con la sociedad chilena en su conjunto?

Nosotros vinimos acá no solo con los sueños de nuestros pueblos originarios, sino que con los sueños de toda una nación. Tenemos un Estado subsidiario en el que los derechos sociales están en el mercado y es el mercado el que hay que cambiar porque es él el que le pone precio a la salud, a la educación, a la vivienda. Nuestro anhelo es que podamos materializar ese grito que salió de las calles, que pedía un cambio transformador y no un mero maquillaje. Nosotros vinimos a la Convención a hacer cambios reales, no ha maquillar ni mejorar nada, realmente vinimos a cambiarlo todo. ¿Y para qué? Para darle dignidad a nuestra gente, y eso es por lo que la mayoría de los que estamos dentro de las diferentes comisiones temáticas estamos luchando por alcanzar. Hay una minoría al interior, que no alcanza a ser el tercio, que solo busca obstaculizar este proceso para que estos cambios no se materialicen, con el fin de proteger sus propios privilegios y seguir con el modelo abusivo que existe al amparo de la constitución de la dictadura.

Por último, uno de los temas que ha estado presente - y que ha sido novedoso para la institucionalidad chilena- junto con los escaños reservados para los pueblo originarios, es el tema de género, pero en particular el debate sobre la paridad. ¿Cuáles cree usted 
que serían las herramientas o las políticas públicas que la constitución debería considerar o establecer para abordar situaciones de discriminación con respecto a las mujeres $y$ a las diversidades sexoafectivas de modo de avanzar efectivamente en paridad?

Bueno, este órgano constituyente es un órgano plurinacional y paritario, que no se dio porque al Estado se le haya ocurrido o haya querido que fuese así, o porque la clase política se haya reunido y haya dicho: «Oye, este órgano constituyente tiene que ser paritario y plurinacional». No. Cuando se hizo el Acuerdo por la Paz, que para nosotros no tiene nada de paz, sino que simplemente fue un salvavidas que le tiraron al presidente porque tenía la situación desbordada, se dejó afuera a las mujeres por considerarlas minoría - siempre se nos ha considerado como una minoría pese a que somos mayoría - y se dejó afuera a los pueblos originarios, pero vino el 8 de marzo y el poder femenino, el poder de las mujeres en la gran marcha del $8 \mathrm{M}$ logró doblar la mano, logró instalar la paridad en el órgano constituyente. Luego, también nosotros, por muchos meses, a casi 11 días de que se cerraran las inscripciones, logramos los escaños reservados. Esos son grandes avances y se han instalado al interior de la Convención: el sexo históricamente excluido y discriminado no puede ser menos del 50\% y el sexo que siempre ha abusado, que en este caso es el sexo masculino, no puede ser más del $60 \%$ en ningunas de las comisiones. Eso se ha respetado y se ha luchado para que se dé en esa lógica. De la misma manera, nosotros estamos luchando en todas las comisiones para que quede instalado el Estado paritario, plurinacional y ecológico.

Muchas gracias por sus respuestas, ¿quisiera agregar algo más, algo que le interese transmitir a la gente?

Solo agregar que desde los 15 años he luchado contra la dictadura, que sufrí vulneraciones a mis derechos humanos y que soy ex presa política, por lo tanto, que a mí me toca mucho la lucha incansable que hemos dado como pueblos originarios, por la discriminación histórica que hemos sufrido, y como pueblo de Chile, por la lucha que dimos contra la dictadura. Todo esto es un símbolo gigante para poner la última piedra sobre Pinochet y Jaime Guzmán.

\section{Sobre la autora}

Claudia Iriarte Rivas es abogada de la Facultad de Derecho de la Universidad de Chile, doctora en Derecho y profesora asistente en la misma universidad. Imparte la Cátedra de Historia del Derecho I y II, y el curso de Género y Derecho. Es investigadora del Centro de Derechos Humanos y, actualmente, editora del Anuario de Derechos Humanos. Su correo es ciriarter@derecho.uchile.cl. (D) https://orcid. org/0000-0003-0449-926X. 